\title{
Cardiovascular Disease Risk Factors Among Women Veterans at VA Medical Facilities
}

\author{
Varsha G. Vimalananda, MD, MPH ${ }^{1,2}$, Donald R. Miller, $S C D^{1,3}$, Cindy L. Christiansen, PhD ${ }^{1,3}$, \\ Wenyu Wang, $\mathrm{MS}^{7}$, Patricia Tremblay, $\mathrm{MMS}^{7}$, and B. Graeme Fincke, $\mathrm{MD}^{1,3}$ \\ 'Center for Health Quality, Outcomes and Economic Research (CHQOER), Edith Nourse Rogers Memorial VA Medical Center, Bedford, MA, USA; \\ ${ }^{2}$ Department of Medicine, Section of Endocrinology, Diabetes and Nutrition, Boston University School of Medicine, Boston, MA, USA; ${ }^{3}$ Department \\ of Health Policy and Management, Boston University School of Public Health, Boston, MA, USA.
}

\begin{abstract}
BACKGROUND: Hypertension, hyperlipidemia, diabetes, and obesity in middle adulthood each elevate the long-term risk of cardiovascular disease (CVD). The prevalence of these conditions among women veterans is incompletely described.
\end{abstract}

OBJECTIVE: To describe the prevalence of CVD risk factors among women veterans in middle adulthood.

DESIGN: Serial cross-sectional studies of data from the Diabetes Epidemiologic Cohorts (DEpiC), a national, longitudinal data set including information on all patients in the Veterans Health Administration (VA).

PARTICIPANTS: Women veterans $(n=255,891)$ and men veterans $(n=2,271,605)$ aged $35-64$ receiving VA care in fiscal year (FY) 2010.

MAIN MEASURES: Prevalence of CVD risk factors in FY2010 by age and, for those aged $45-54$ years, by race, region, period of military service, priority status, and mental illness or substance abuse; prevalence by year from 2000 to 2010 in women veterans receiving VA care in both 2000 and 2010 who were free of the factor in 2000.

KEY RESULTS: Hypertension, hyperlipidemia, and diabetes were common among women and men, although more so among men. Hypertension was present in $13 \%$ of women aged 35-44 years, $28 \%$ of women aged 45-54, and $42 \%$ of women aged 55-64. Hyperlipidemia prevalence was similar. Diabetes affected $4 \%$ of women aged 35-44, and increased more than four-fold in prevalence to $18 \%$ by age 55-64. The prevalence of obesity increased from $14 \%$ to $18 \%$ with age among women and was similarly prevalent in men. The relative rate of having two or more CVD risk factors in women compared to men increased progressively with age, from 0.55 (35-44 years) to $0.71(45-54)$ to 0.73 (55-64). Most of the women with a factor present in 2010 were first diagnosed with the condition in the 10 years between 2000 and 2010.

CONCLUSIONS: CVD risk factors are common among women veterans aged 35-64. Future research should investigate which interventions would most effectively reduce risk in this population.

Electronic supplementary material The online version of this article (doi:10.1007/s11606-013-2381-9) contains supplementary material, which is available to authorized users.
KEY WORDS: women; veterans; epidemiology; cardiovascular disease; risk factors.

J Gen Intern Med 28(Suppl 2):S517-23

DOI: $10.1007 / \mathrm{s} 11606-013-2381-9$

(c) Society of General Internal Medicine 2013

\section{INTRODUCTION}

Cardiovascular disease (CVD) remains the leading cause of death among women and men in the United States. ${ }^{1}$ The presence of even one major CVD risk factor at age 50 years substantially raises the lifetime risk of CVD, and is associated with lower survival in the general population. ${ }^{2}$ Veterans of military service receiving care from the Veterans Health Administration (VA) may be at even higher risk of CVD than the general population. since they often have poorer health status and more medical conditions. ${ }^{3,4}$ In addition, veteran patients have higher rates of mental illnesses such as depression and PTSD, which are associated with increased CVD risk. ${ }^{5,6}$ Women represent a growing segment of the veteran population that has not been fully characterized with respect to CVD risk. ${ }^{7,8}$ As compared to men, women veterans carry a similar burden of overall physical and mental health conditions, but are of lower mean age and have less social support. ${ }^{9}$ Previous studies indicate a high prevalence of CVD risk factors among adult women in the general population (hypertension, $29 \% ;{ }^{10}$ hyperlipidemia, $42 \% ;{ }^{11}$ diabetes, $8 \% ;^{12}$ and obesity, $36 \%{ }^{13}$ ). Understanding the pattern of CVD risk factors among women veterans can inform efforts to ultimately prevent or delay the onset of CVD in this group.

The objectives of the present study were to describe the prevalence of CVD risk factors in women veterans of middle adulthood in fiscal year (FY) 2010 receiving VA care, to examine how the distribution of these risk factors varies by various demographic factors, mental illnesses, and substance abuse, and to describe changes in the prevalence of each risk factor from FY2000 to FY2010 among women who were free of that condition in FY2000. For reference, we present prevalence data 
for men veterans receiving VA care alongside that of women.

\section{METHODS}

We conducted serial cross-sectional studies using data from the VA Diabetes Epidemiology Cohort (DEpiC), a national, longitudinal data set including information on all patients in the VA since 1998. DEpiC is constructed from multiple national computerized data files in the VA, and includes information on medical encounters, prescriptions, laboratory tests, mortality, Medicare claims data for VA patients, and VA patient survey data. ${ }^{14}$ We included all veterans aged 35-64 years who were receiving healthcare from the VA in fiscal year (FY) 2010 and had at least two services in the 24-month period of FY 2009-2010.

Demographic characteristics included age, race, region, period of military service, priority status, and healthcare utilization. Race data in DEpiC combines information from VA records, Medicare claims, and the 1999 Large Health Survey of Veteran Enrollees, ${ }^{15}$ with preferential use of selfreported measures; race was still missing for many patients (see Table 1). We assigned patients to one of four US census regions based on the location of the care facility where they had the most visits in FY 2010. Patients were classified by period of military service (Vietnam War era and before; post-Vietnam era; Persian Gulf War/Operation Enduring Freedom (OEF)/ Operation Iraqi Freedom (OIF); and other, which includes a mix of unknown and active service). Priority status is a measure of a veteran's eligibility for VA services that we used as a proxy for economic and disability status. Priority status was grouped into four categories: full disability (no co-pay for prescriptions and visits: priority groups 1 and 4); poverty (no co-pay: priority group 5); part disability (variable co-pay: priority groups 2, 3, 6 and 9) and co-pay (priority groups 7 and 8, with neither disability nor poverty). Healthcare utilization was defined by the number of outpatient visits in the year, and by whether an individual had any inpatient service during the year.

Prevalence rates were estimated as the percent of those in the sample who were classified as having the condition in the year. Each clinical condition was identified on the basis of at least 2 days with ICD-9-CM codes recorded from inpatient or outpatient medical encounters in the 24-month period of FY2009-2010. Diabetes also was assigned if the patient was dispensed a diabetes medication in FY2010. ${ }^{14}$ Codes and medications used to identify the conditions are listed in online Appendix 1. Obesity was identified solely on the basis of ICD-9-CM codes, because sufficient measures of height and weight were not available for the study time periods. We considered hypertension, hyperlipidemia, diabetes, and obesity to be CVD risk factors. In our prior work, we found that only $6 \%$ of VA patients with diabetes would not be identified with use of VA data alone. ${ }^{14}$ We therefore found it likely that VA patients with an index CVD condition would have come to the VA for care and had that condition documented.

Women and men were stratified by decade of age in FY2010: 35-44; 45-54; and 55-64 years. For each group, we calculated frequencies for demographic and clinical characteristics in FY2010. For the veterans aged 4554 years, we present prevalence of CVD risk factors by category of race, region, period of military service, priority status, and presence of mental health conditions and substance abuse. For each age group, we calculated the relative rate of having $2+$ CVD risk factors in women compared to men by dividing the rate of each condition in women by that in men. For example, in age group 35-44 the relative rate was $11 \% \div 20 \%=55 \%$.

To establish fixed cohorts and examine the emergence of CVD risk factors over a 10-year period, the overall sample of veterans, aged 35-64 years, receiving healthcare from the VA in FY2010 (with at least two services in the 24-month period of FY2009-2010) was limited to those who also received care from the VA in FY2000 (with at least two services in the 24-month period of FY1999-2000). Conditions in earlier years were identified using the same methods described above for FY2010. In this sample, we calculated prevalence of CVD risk factors in FY2010 and in FY2000. Then, in women without the factor in FY2000 (35-44 year: $N=$ 17,934; 45-54 year: $N=38,479$; 55-64 year: $N=35,703$ ), we calculated the cumulative annual incidence of the factor in FY2001 as the proportion of those with the factor during that year from among those without it in the prior year. This was added to the baseline prevalence from FY2000 to obtain an estimate of period prevalence for FY2000-2001. This process was repeated for each year between FY2000 and FY2010, calculating incidence proportion for each year in those without the factor in prior years, and adding it to the period prevalence from the prior year. This provided running period prevalences for those years, which we present as smoothed plots. Though we did not require that patients receive VA care in every year from FY2000 through FY2010, $67 \%$ of women and $75 \%$ of men in our sample did receive VA care continuously during this period, and the plots derived in the sample of patients with continuous service use were similar.

Statistical analyses were performed using SAS version 9.2 (SAS Institute Inc, Cary, North Carolina). Institutional review board approval was obtained from the Bedford VA Medical Center Institutional Review Board.

\section{RESULTS}

Our sample included 255,891 women and 2,271,605 men aged 35-64 years (Table 1). Across age groups, women were more commonly Black, living in the South, and 
Table 1. Demographic and Clinical Characteristics of Women and Men Veterans Aged 35-64 Years in 2010*

\begin{tabular}{|c|c|c|c|c|c|c|}
\hline & \multicolumn{2}{|l|}{ 35-44 years } & \multicolumn{2}{|l|}{ 45-54 years } & \multicolumn{2}{|l|}{ 55-64 years } \\
\hline & $\begin{array}{l}\text { Women } \\
(n=66,976)\end{array}$ & $\begin{array}{l}\text { Men } \\
(n=278,752)\end{array}$ & $\begin{array}{l}\text { Women } \\
(n=105,075)\end{array}$ & $\begin{array}{l}\text { Men } \\
(n=572,678)\end{array}$ & $\begin{array}{l}\text { Women } \\
(n=83,840)\end{array}$ & $\begin{array}{l}\text { Men } \\
(n=1,420,175)\end{array}$ \\
\hline \multicolumn{7}{|l|}{ Race $\dagger$} \\
\hline White & 54 & 64 & 59 & 60 & 70 & 75 \\
\hline Black & 37 & 26 & 34 & 31 & 22 & 17 \\
\hline Hispanic & 5 & 6 & 4 & 5 & 4 & 4 \\
\hline Other & 5 & 4 & 4 & 4 & 4 & 3 \\
\hline \multicolumn{7}{|l|}{ Region } \\
\hline Northeast & 12 & 12 & 13 & 12 & 14 & 13 \\
\hline South & 51 & 46 & 50 & 46 & 46 & 43 \\
\hline Midwest & 17 & 20 & 18 & 20 & 18 & 22 \\
\hline West & 20 & 22 & 20 & 21 & 23 & 22 \\
\hline \multicolumn{7}{|l|}{ Period of military service } \\
\hline Vietnam War era and before & 0 & 0 & 5 & 15 & 35 & 89 \\
\hline Post-Vietnam War era & 14 & 19 & 40 & 53 & 16 & 5 \\
\hline Persian Gulf War/OEF/OIF ${ }^{\star}$ & 66 & 75 & 33 & 29 & 15 & 5 \\
\hline Other & 20 & 6 & 22 & 3 & 35 & 1 \\
\hline \multicolumn{7}{|l|}{ Priority status $\S$} \\
\hline Full disability & 22 & 21 & 23 & 19 & 19 & 21 \\
\hline Poverty & 16 & 18 & 22 & 27 & 26 & 21 \\
\hline Part disability & 54 & 53 & 47 & 45 & 44 & 47 \\
\hline Co-pay & 7 & 8 & 8 & 10 & 11 & 11 \\
\hline \multicolumn{7}{|l|}{ Healthcare utilization } \\
\hline Outpatient visit in the year (mean $\pm \mathrm{SD})$ & $12 \pm 16$ & $11 \pm 17$ & $14 \pm 20$ & $15 \pm 22$ & $14 \pm 18$ & $15 \pm 19$ \\
\hline Any inpatient visit in the year & 6 & 7 & 7 & 11 & 7 & 11 \\
\hline \multicolumn{7}{|l|}{ Mental illness/Substance abuse } \\
\hline Major depression & 27 & 22 & 28 & 23 & 26 & 21 \\
\hline Bipolar disorder & 7 & 6 & 7 & 6 & 5 & 3 \\
\hline Anxiety disorder & 12 & 10 & 11 & 9 & 10 & 7 \\
\hline Post-traumatic stress disorder & 13 & 15 & 13 & 8 & 9 & 17 \\
\hline Schizophrenia & 1 & 2 & 2 & 4 & 2 & 3 \\
\hline Alcohol or substance abuse & 6 & 13 & 8 & 20 & 5 & 13 \\
\hline Tobacco use & 10 & 15 & 17 & 24 & 14 & 22 \\
\hline
\end{tabular}

*All values are \% unless otherwise specified

†Missing values for race are: Age 35-44 W $25 \%$, M $17 \%$; Age 45-54 W $23 \%$, M $13 \%$; Age 55-64 W 23\%; Men 12 \% Enduring Freedom/Operation Iraqi Freedom

\$Missing values for priority status are: Age 35-44 W $4 \%, \mathrm{M} 4 \%$; Age 45-54 W $4 \%$, M $2 \%$; Age 55-64 W $3 \%$; Men $2 \%$

diagnosed with major depression, bipolar disorder, or anxiety disorder, whereas men were more often hospitalized, used tobacco, and carried a diagnosis of schizophrenia, alcohol abuse, or substance abuse.

The prevalence of hypertension, hyperlipidemia, and diabetes was high in both women and men, although each was more common among men (Fig. 1). Hypertension and hyperlipidemia were more common than diabetes, while all three conditions increased in frequency with increasing age. Hypertension was present in $13 \%$ of women aged $35-$ 44 years, $28 \%$ of women aged $45-54$, and $42 \%$ of women aged 55-64. Hyperlipidemia was very similar in prevalence. Diabetes affected $4 \%$ of women aged $35-44$, but increased more than four-fold by age 55-64 to a prevalence of $18 \%$. Obesity followed a different pattern. It was diagnosed more commonly among women and the prevalence increased less with age - from $14 \%$ to $18 \%$ in women and from $14 \%$ to $17 \%$ in men. The prevalence of women with $2+$ risk factors increased from $11 \%$ to $24 \%$ to $38 \%$ with age, and among men it increased from $20 \%$ to $34 \%$ to $52 \%$. The relative rate of having two or more CVD risk factors in women as compared to men also increased progressively, from 0.55 (35-44 years) to $0.71(45-54)$ to 0.73 (55-64).
Prevalence of CVD risk factors among 45-54 year old women and men VA patients showed variation by race, region, priority status and mental health condition (Table 2). Among race groups, Blacks had the highest prevalence of hypertension (women $45 \%$; men $50 \%$ ) and the lowest prevalence of hyperlipidemia (women $28 \%$; men $35 \%$ ). Among both women and men, whites had the lowest prevalence of diabetes as well as lower prevalence of obesity compared to Blacks or Hispanics. Those with full disability as a basis for VA eligibility (priority status) had the highest prevalence of all conditions compared to those with other priority status. Among those with mental illness, diabetes was most common among those with schizophrenia (women $24 \%$; men $25 \%$ ). While the overall prevalence of obesity among women 45-54 years old was $17 \%$ (Fig. 1), the prevalence of obesity among women of this age group with schizophrenia was more than doubled at $36 \%$. Of women 45-54 years old with depression, $38 \%$ had hypertension, $40 \%$ had hyperlipidemia, $14 \%$ had diabetes, and $25 \%$ were obese.

While Fig. 1 displays the prevalence of CVD risk factors among women in FY2010, Fig. 2 displays the prevalence of disease in FY2000, as well as the increase in risk factor 
Hypertension

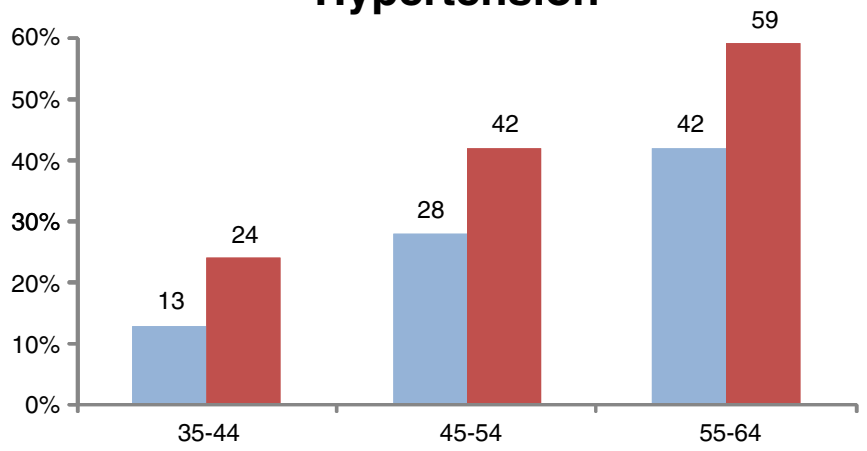

Diabetes

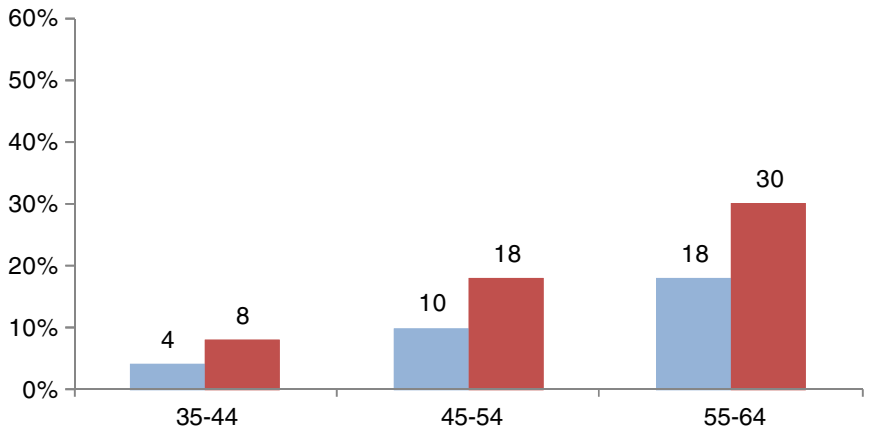

Hyperlipidemia

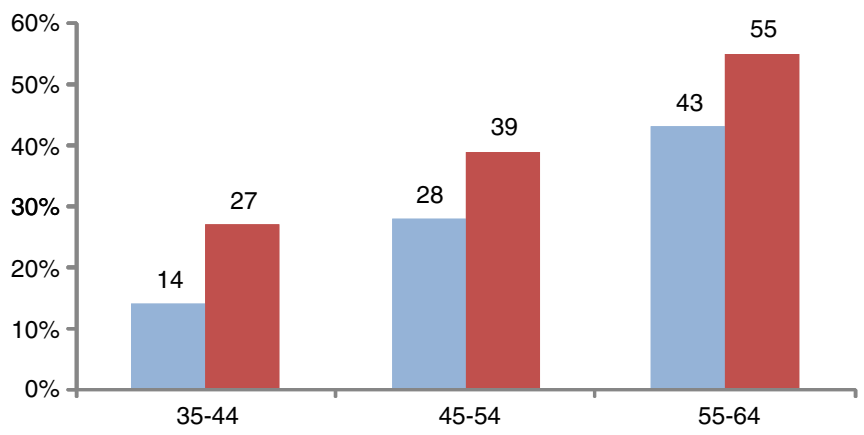

Obesity

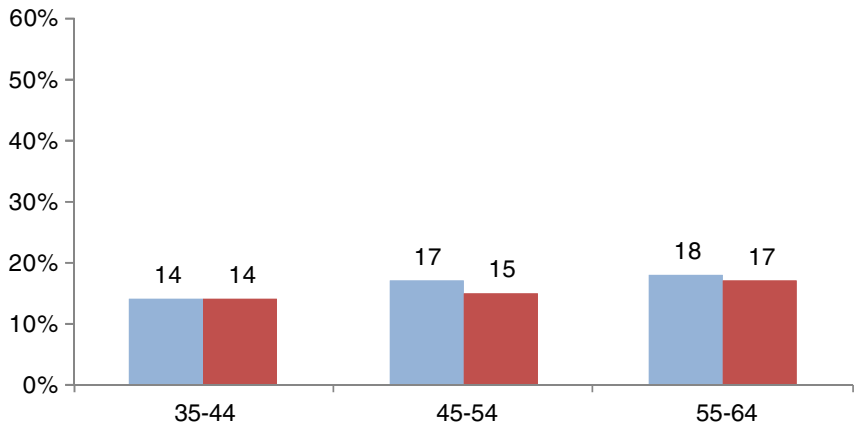

Women $\square$ Men

Figure 1. Prevalence of CVD risk factors in women and men veterans aged 35-64 years in 2010.

prevalence from FY2000-FY2010 among women who were free of each condition in FY2000, stratified by age in FY2010. Most of the women with a factor present in 2010 developed the condition in the 10 years between 2000 and 2010. The prevalence of each condition increased substantially across the decade in all age groups, with increases of more than five-fold in rates in several categories. In some cases, the secular trend (increase over time) exceeded the increase with age. This was particularly striking for obesity. We found that the prevalence of obesity in FY2010 among the cohort who was $45-54$ in that year was much higher than the prevalence in the older cohort when they were that age (in FY2000), suggesting an earlier emergence of disease among the younger cohort. Large increases over time were found for the other risk factors, but also with substantial increases across the age groups.

\section{DISCUSSION}

We demonstrate that women veterans have high rates of CVD risk factors. While men have a higher prevalence of hypertension, hyperlipidemia, and diabetes, the gap in overall risk factor burden narrows with increasing age.
About one-quarter of women veterans in VA have more than two CVD risk factors at age 45-54 years; this increases to over one-third in women aged 55-64 years. Given the strong association of CVD risk factors in mid-adulthood with increased long-term CVD risk, ${ }^{2}$ the synergistic risk posed by the presence of more than one risk factor, ${ }^{16}$ and the increasing numbers of women serving in the military, these findings portend a significant future burden of CVD among women veterans receiving care in the VA. Therefore, interventions to reduce CVD risk among veterans should be designed with both women and men in mind.

An overview of CVD risk factors among women veterans has heretofore been lacking. Using ICD-9 codes, Yoon et al. reported that hypertension was the most commonly diagnosed condition among all woman veteran VA patients in $2008(206.7 / 1000){ }^{7}$ Diabetes was diagnosed in 86.3/1000. We found a higher prevalence of both conditions, but our study is limited to women of middle adulthood, which eliminates younger women who would have a low prevalence by virtue of their age. In addition, Yoon et al. ascertained diagnoses on the basis of two ICD-9 codes in a single fiscal year. We used a 2-year time period to identify codes, which would capture more patients, and by including medication use, we utilize a more sensitive definition of 
Table 2. Cardiovascular Disease (CVD) Risk Factors by Race, Region, Period of Military Service, Priority Status and Mental Illness/ Substance Abuse for Women and Men Veterans Aged 45-54 Years in 2010*

\begin{tabular}{|c|c|c|c|c|c|c|c|c|c|c|}
\hline \multirow[b]{3}{*}{ Total (N) } & \multicolumn{2}{|l|}{ Total } & \multicolumn{2}{|c|}{ Hypertension } & \multicolumn{2}{|c|}{ Hyperlipidemia } & \multicolumn{2}{|l|}{ Diabetes } & \multicolumn{2}{|l|}{ Obesity } \\
\hline & Women & Men & Women & Men & Women & Men & Women & Men & Women & Men \\
\hline & 105,075 & 572,678 & 29,372 & 237,888 & 29,220 & 225,922 & 10,767 & 100,582 & 17,605 & 88,119 \\
\hline \multicolumn{11}{|l|}{ Race } \\
\hline White & 47,498 & 298,345 & 26 & 40 & 35 & 43 & 10 & 17 & 18 & 16 \\
\hline Black & 27,291 & 155,611 & 45 & 50 & 28 & 35 & 15 & 20 & 22 & 15 \\
\hline Hispanic & 2,904 & 26,210 & 26 & 41 & 36 & 47 & 13 & 24 & 22 & 21 \\
\hline Other & 3,259 & 18,271 & 31 & 42 & 33 & 42 & 15 & 22 & 18 & 15 \\
\hline \multicolumn{11}{|l|}{ Region } \\
\hline Northeast & 13,235 & 70,787 & 22 & 38 & 26 & 41 & 9 & 16 & 18 & 19 \\
\hline South & 52,244 & 264,462 & 32 & 45 & 29 & 41 & 11 & 18 & 17 & 15 \\
\hline Midwest & 18,402 & 114,409 & 27 & 42 & 30 & 42 & 10 & 18 & 17 & 15 \\
\hline West & 21,194 & 123,020 & 23 & 36 & 24 & 34 & 9 & 16 & 15 & 14 \\
\hline \multicolumn{11}{|l|}{ Period of military service } \\
\hline Vietnam war and before & 4,830 & 85,233 & 39 & 48 & 40 & 41 & 17 & 22 & 22 & 16 \\
\hline Post- Vietnam war era & 42,145 & 305,333 & 34 & 43 & 33 & 39 & 13 & 19 & 21 & 16 \\
\hline Persian Gulf/OEF/OIF ${ }^{*}$ & 34,556 & 167,189 & 29 & 38 & 29 & 41 & 9 & 14 & 18 & 15 \\
\hline Other & 23,544 & 14,923 & 13 & 15 & 14 & 16 & 5 & 6 & 7 & 6 \\
\hline \multicolumn{11}{|l|}{ Priority status } \\
\hline Full disability & 23,017 & 103,448 & 32 & 45 & 33 & 45 & 12 & 20 & 20 & 18 \\
\hline Poverty & 22,478 & 151,894 & 28 & 41 & 25 & 35 & 11 & 18 & 16 & 14 \\
\hline Part disability & 48,189 & 250,482 & 27 & 42 & 27 & 41 & 10 & 17 & 16 & 16 \\
\hline Co-pay & 8,549 & 53,198 & 27 & 41 & 28 & 41 & 10 & 18 & 16 & 15 \\
\hline \multicolumn{11}{|l|}{ Mental illness/Substance abuse } \\
\hline Major depression & 29,247 & 129,992 & 38 & 49 & 40 & 47 & 14 & 21 & 25 & 20 \\
\hline Bipolar disorder & 7,853 & 36,193 & 35 & 46 & 40 & 46 & 16 & 20 & 27 & 20 \\
\hline Anxiety disorder & 12,080 & 50,620 & 37 & 48 & 40 & 48 & 13 & 17 & 24 & 18 \\
\hline Post traumatic stress disorder & 13,157 & 48,214 & 35 & 47 & 38 & 46 & 14 & 18 & 26 & 19 \\
\hline Schizo- phrenia & 2,333 & 22,050 & 42 & 47 & 41 & 45 & 24 & 25 & 36 & 21 \\
\hline Alcohol, substance abuse & 8,598 & 111,823 & 40 & 47 & 34 & 36 & 12 & 16 & 20 & 14 \\
\hline Tobacco cessation treatment & 17,542 & 138,642 & 39 & 48 & 45 & 46 & 13 & 18 & 21 & 16 \\
\hline
\end{tabular}

* Prevalence of CVD risk factors is expressed as the percent of women and men in each demographic group who have factor $\ddagger O E F / O I F=$ Operation Enduring Freedom/Operation Iraqi Freedom.

diabetes. ${ }^{14}$ Most other reports of CVD risk factor prevalence among veterans do not stratify results by sex, ${ }^{17,18}$ but we demonstrate that hypertension, hyperlipidemia, and diabetes are less common among women, while obesity is similarly prevalent between sexes. A prior study of obesity prevalence in the VA using height and weight data from clinical encounters found more obesity among women than men, ${ }^{19}$ which supports our finding that the gender distribution of obesity is different from that of hypertension, hyperlipidemia or diabetes.

Cardiovascular disease risk reduction presents a significant challenge to the healthcare system. Diet and exercise are effective methods of weight loss to prevent or delay CVD and diabetes, but behavior change interventions, such as those of the Diabetes Prevention Program, are resource-intensive and difficult to sustain at the local level. ${ }^{20}$ The effectiveness of such interventions is also critically dependent on how they are implemented. ${ }^{21}$ For those who have already developed risk factors, adherence to medication is as important as lifestyle modification. However, a Cochrane review of interventions to improve adherence found that even the most effective methods of promoting adherence to medications for chronic conditions showed only modest improvements. ${ }^{22}$ A novel intervention utilizing storytelling to promote behavior change demonstrated reductions in blood pressure among inner-city African
Americans that were comparable or better than many other behavioral and pharmacologic interventions. ${ }^{23}$ Whether this strategy could be equally effective for other chronic conditions in other populations, including veteran women and men, has yet to be confirmed.

The question remains as to whether any interventions to reduce CVD risk should be different for women and men. We did not examine the modifying effects of depression or other patient characteristics on the incidence of CVD risk factors, which may be very different between women and men. Women also have sex-specific barriers to behavior change and adherence, such as their inaccurately low perception of CVD risk, ${ }^{24}$ as well as significant childcare and eldercare responsibilities. ${ }^{25}$ Certain aspects of healthcare content and delivery are valued differently by women and men, ${ }^{26,27}$ and women-tailored primary care is associated with higher satisfaction among women veterans. ${ }^{28}$ Therefore, there are several potential reasons to develop sex-specific CVD risk reduction interventions that remain incompletely explored.

Our study has several limitations. Use of ICD-9-CM codes may underestimate the true prevalence of disease. ${ }^{29}$ Although our use of two diagnoses within a 2-year period is a highly sensitive method of detecting hyperlipidemia and diabetes, and is supported by other studies, ${ }^{14,29,30}$ it is likely that obesity rates were underestimated. The previously cited 

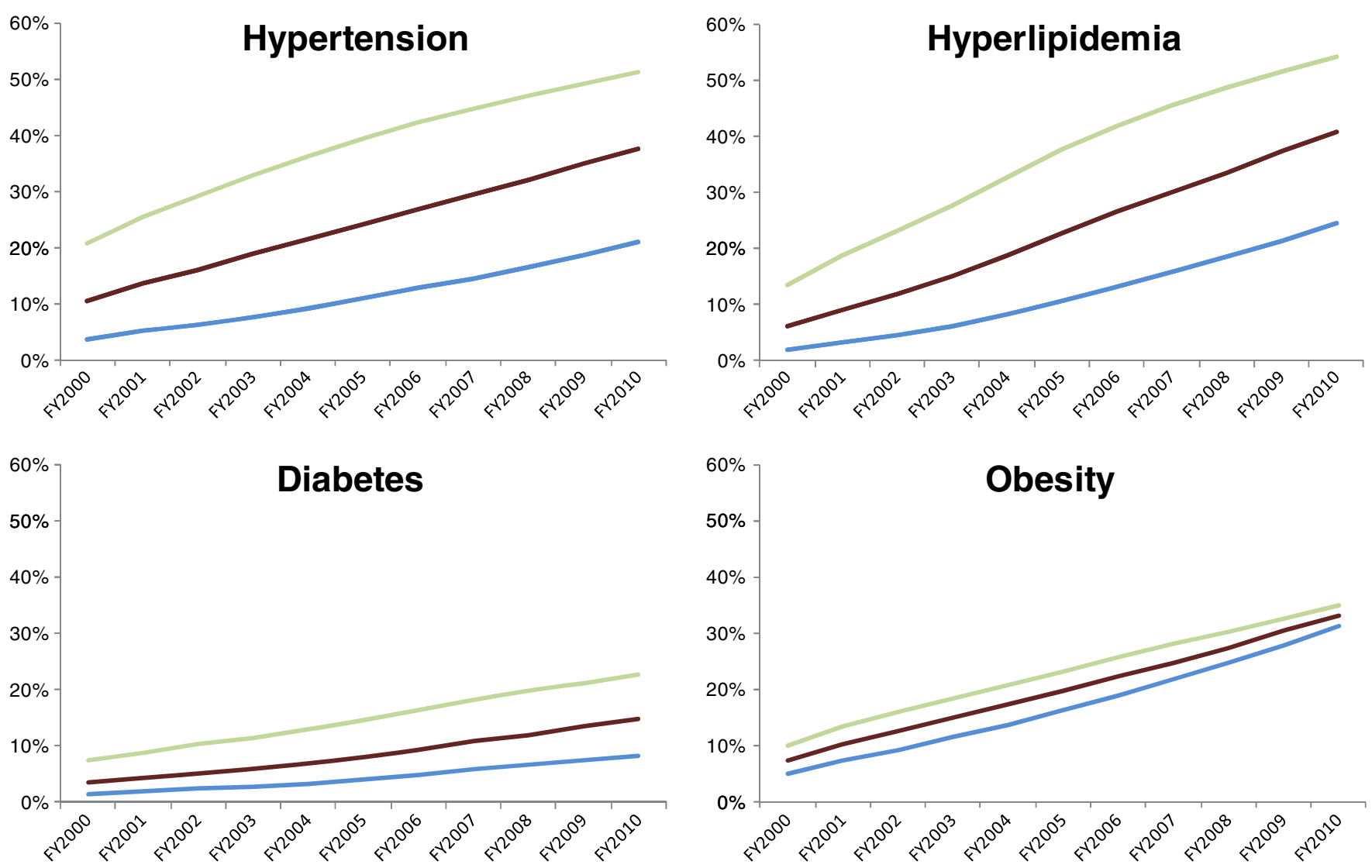
35-44 years 45-54 years $55-64$ years

Figure 2. Prevalence of CVD risk factors in women veterans by age from $2000-2010 * \%$ *For this analysis, the population of women was restricted to those who received VA care in both FY2000 and FY2010. $\dagger$ Plots are smoothed. Lines represent connections between annual rates. \$Annual rates were derived as follows: in the restricted population, prevalence of risk factors was calculated in FY2000 and FY2010. In women without the factor in FY2000, the cumulative annual incidence was calculated as the proportion of those with the factor during that year from among those without it in the prior year. This was added to the baseline prevalence from FY2000 to estimate the period prevalence for FY2000-2001. This process was repeated for each year between FY2000 and FY2010, calculating incidence proportion for each year in those without the factor in prior years and adding it to the period prevalence from the prior year.

study using height and weight data from clinical encounters found higher obesity rates of approximately $30 \%,{ }^{19}$ which calls into question the accuracy of provider coding practices around obesity. There were high rates of missing race data and women had higher rates of missing data than men in each age cohort. The limitations of race data in the VA are well-documented, ${ }^{31}$ but we are not aware of a basis for a sex difference in these limitations. We did not use data on fee-basis care for hypertension, hyperlipidemia, and obesity in each year of the study, as we have found it to be less reliable and complete than other VA utilization data. However, we did conduct a sensitivity analysis using 2010 fee-basis data to assess the degree to which we might be missing prevalent conditions. We found that for both sexes, addition of fee-basis data in 2010 would add a similar percent of cases, but that these new cases would comprise less than $0.025 \%$ of the overall sample for each condition. Patients with a condition at any time were not included in the denominator in subsequent years, as our focus was on calculating annual incidence of CVD risk factors. Fluctuations in obesity, therefore, would not be accounted for.

In conclusion, we find high rates of cardiovascular disease risk factors among women veterans in middle adulthood, with an apparent earlier emergence of disease among younger cohorts. This will likely translate to a significant burden of CVD with associated suffering, healthcare costs, and mortality in the future. The VA already supports sex-specific quality improvement measures and is promoting efforts to increase military women's awareness of CVD through partnership with the AHA's "Go Red for Women" campaign. Future research can help to understand what additional strategies to reduce the risk of CVD in women veterans might be most effective.

Acknowledgements: This study was supported by the Department of Veterans Affairs, Veterans Health Administration, Office of Research and Development, Health Services Research and Development. 
Conflict of Interest: The authors declare that they do not have a conflict of interest.

Disclaimer: The views expressed in this article are those of the authors and do not necessarily reflect the position or policy of the Department of Veterans Affairs or the United States government.

Corresponding Author: Varsha G. Vimalananda, MD, MPH; Center for Health Quality, Outcomes and Economic Research (CHQOER), Edith Nourse Rogers Memorial VA Medical Center, 200 Springs Road, Building 70 (152), Bedford, MA 01730, USA (e-mail: varsha.vimalananda@va.gov).

\section{REFERENCES}

1. Centers for Disease Control and Prevention. (2012). Women's Health, Leading Causes of Death in Females, 2008. http://www.cdc.gov/women/ lcod/2008/index.htm. November 19, 2012.

2. Lloyd-Jones DM, Leip EP, Larson MG, D'Agostino RB, Beiser A, Wilson PW, et al. Prediction of lifetime risk for cardiovascular disease by risk factor burden at 50 years of age. Circulation. 2006;113(6):791-8.

3. Kazis LE, Ren XS, Lee A, Skinner K, Rogers W, Clark J, et al. Health status in VA patients: Results from the Veterans Health Study. Am J Med Qual. 1999;14(1):28-3.

4. Agha Z, Lofgren RP, VanRuiswyk JV, Layde PM. Are patients at Veterans Affairs medical centers sicker? A comparative analysis of health status and medical resource use. Arch Intern Med. 2000;160(21):3252-7.

5. Ahmadi N, Hajsadeghi F, Mirshkarlo HB, Budoff M, Yehuda R, Ebrahimi R. Post-traumatic stress disorder, coronary atherosclerosis, and mortality. Am J Cardiol. 2011;108(1):29-33.

6. Jiang W, Glassman A, Krishnan R, O'Connor CM, Califf RM. Depression and ischemic heart disease: What have we learned so far and what must we do in the future? Am Heart J. 2005; 150(1):54-78.

7. Yoon J, Scott JY, Phibbs CS, Frayne SM. Trends in rates and attributable costs of conditions among female VA patients, 2000 and 2008. Womens Health Issues. 2012;22(3):e337-44.

8. Bean-Mayberry B, Yano EM, Washington DL, Goldzweig C, Batuman F, Huang C, Miake-Lye I, Shekelle PG. Systematic review of women veterans' health: update on successes and gaps. Womens Health Issues. 2011;21(4 Suppl):S84-97. Review.

9. Frayne SM, Parker VA, Christiansen CL, Loveland S, Seaver MR, Kazis LE, et al. Health status among 28,000 women veterans. the VA Women's Health Program Evaluation Project. J Gen Intern Med. 2006;21(Suppl 3):S40-6.

10. Egan BM, Zhao Y, Axon R. US trends in prevalence, awareness, treatment, and control of hypertension, 1988-2008. JAMA. 2010;303(20):2043-2050

11. Wong ND, Lopez V, Tang S, Williams GR. Prevalence, treatment, and control of combined hypertension and hypercholesterolemia in the United States. Am J Cardiol. 2006;98(2):204-8.

12. Cowie CC, Rust KF, Ford ES, Eberhardt MS, Byrd-Holt DD, Li C, Williams DE, Gregg EW, Bainbridge KE, Saydah SH, Geiss LS. Full accounting of diabetes and pre-diabetes in the U.S. population in 19881994 and 2005-2006. Diabetes Care. 2009;32(2):287-94.
13. Flegal KM, Carroll MD, Ogden CL, Curtin LR. Prevalence and trends in obesity Among US adults, 1999-2008. JAMA. 2010;303(3):235-241.

14. Miller DR, Safford MM, Pogach LM. Who has diabetes? Best estimates of diabetes prevalence in the Department of Veterans Affairs based on computerized patient data. Diabetes Care. 2004;27(Suppl 2):B10-21.

15. Perlin J, Kazis L, Miller DR, Skinner K, Ren XS, et al. Health status and outcomes of veterans: physical and mental component summary scores: veterans SF-36; 1999 large health survey of veteran enrollees, executive report, veterans health administration, May, 2000.

16. Borghi C. Interactions between hypercholesterolemia and hypertension: Implications for therapy. Curr Opin Nephrol Hypertens. 2002;11(5):489-96.

17. Yu W, Ravelo A, Wagner TH, Phibbs CS, Bhandari A, Chen S, et al. Prevalence and costs of chronic conditions in the VA health care system. Med Care Res Rev. 2003;60(3 Suppl):146S-67.

18. Johnson ML, Pietz K, Battleman DS, Beyth RJ. Prevalence of comorbid hypertension and dyslipidemia and associated cardiovascular disease. Am J Manag Care. 2004;10(12):926-32.

19. Das SR, Kinsinger LS, Yancy WS Jr, Wang A, Ciesco E, Burdick M, et al. Obesity prevalence among veterans at Veterans Affairs medical facilities. Am J Prev Med. 2005;28(3):291-4.

20. Crandall JP, Knowler WC, Kahn SE, Marrero D, Florez JC, Bray GA et al. The prevention of type 2 diabetes. Nat Clin Pract Endocrinol Metab. 2008;4(7):382-93.

21. Kahwati LC, Lewis MA, Kane H, Williams PA, Nerz P, Jones KR, et al Best practices in the Veterans Health Administration's MOVE! weight management program. Am J Prev Med. 2011;41(5):457-64.

22. Haynes RB, Ackloo E, Sahota N, McDonald HP, Yao X. Interventions for enhancing medication adherence. Cochrane Database Syst Rev. 2008;16(2):CD000011.

23. Houston TK, Allison JJ, Sussman M, Horn W, Holt CL, Trobaugh J, et al. Culturally appropriate storytelling to improve blood pressure: A randomized trial. Ann Intern Med. 2011;154(2):77-84.

24. Biswas MS, Calhoun PS, Bosworth HB, Bastian LA. Are women worrying about heart disease? Womens Health Issues. 2002;12(4):204-11.

25. Mosca L, Mochari H, Christian A, Berra K, Taubert K, Mills T, et al National study of women's awareness, preventive action, and barriers to cardiovascular health. Circulation. 2006;113(4):525-34.

26. Weisman CS, Rich DE, Rogers J, Crawford KG, Grayson CE, Henderson JT. Gender and patient satisfaction with primary care: Tuning in to women in quality measurement. J Womens Health Gend Based Med. 2000;9(6):657-65.

27. Kressin NR, Skinner K, Sullivan L, Miller DR, Frayne S, Kazis L, et al. Patient satisfaction with department of Veterans Affairs health care: Do women differ from men? Mil Med. 1999;164(4):283-8.

28. Washington DL, Bean-Mayberry B, Mitchell MN, Riopelle D, Yano EM. Tailoring VA primary care to women veterans: Association with patientrated quality and satisfaction. Womens Health Issues. 2011;21(4 Suppl): S112-9.

29. Borzecki AM, Wong AT, Hickey EC, Ash AS, Berlowitz DR. Identifying hypertension-related comorbidities from administrative data: What's the optimal approach? Am J Med Qual. 2004;19(5):201-6.

30. Saydah SH, Geiss LS, Tierney E, Benjamin SM, Engelgau M, Brancati F. Review of the performance of methods to identify diabetes cases among vital statistics, administrative, and survey data. Ann Epidemiol. 2004; 14(7):507-16

31. Sohn MW, Zhang H, Arnold N, Stroupe K, Taylor BC, Wilt TJ, et al. Transition to the new race/ethnicity data collection standards in the Department of Veterans Affairs. Popul Health Metr. 2006;4:7. 